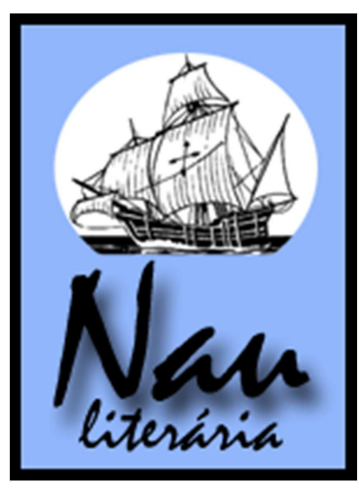

\title{
A cidade da flânerie, do vazio e da errância em Estorvo, de Chico Buarque
}

\section{Ewerton de Freitas Ignácio}

\begin{abstract}
Resumo: Este artigo tem por objetivo realizar uma leitura de Estorvo, publicado por Chico Buarque em 1991, tentando evidenciar que esse romance se configura como uma poética urbana do vazio e da errância individual, poética que se desdobra por meio das deambulações que o protagonista, aturdidamente, realiza pelas ruas de uma grande cidade. Nesse aspecto, interessa observar de que forma uma narrativa fragmentada - em seu conjunto e na linguagem que a plasma - se coaduna com o retrato da experiência vivida por uma personagem que, em meio a um cenário urbano - com breves referências a elementos do universo rural -, atravessa pela experiência da incompreensão mútua, da violência e da impossibilidade de uma plena comunicação com o outro, sempre na condição de um atarantado e perdido flâneur.
\end{abstract}

Palavras-chave: Chico Buarque; romance brasileiro contemporâneo; flâneur; experiência urbana.

\begin{abstract}
This article aims to perform a reading of Estorvo (1991), by Chico Buarque, trying to show that you have in the work, setting up an urban poetics of emptiness and wandering through the individual unfolded the protagonist wandering dazed and without the right direction, performs on the streets of a big city. In this respect, it is interesting to observe how a fragmented narrative - in whole and in language that conforms - is consistent with the picture of the experience of a character who, in the midst of an urban setting - with brief references to elements of the universe rural - through the experience of mutual incomprehension, violence and the impossibility of a full communication with each other, always in a dazed condition and lost flâneur.
\end{abstract}

Keywords: Chico Buarque; Brazilian contemporary novel; flâneur; urban experience.

Ninguém chega a ser um, nesta cidade

Mário de Andrade, Paulicéia desvairada

\section{Todos os desnorteios, o desnorteio}

É possível observar, no conjunto da obra romanesca de Chico Buarque, uma cuidadosa representação das experiências urbanas vivenciadas por suas personagens. Desse modo é que, em seu último romance, Leite derramado (2009), as recordações de Eulálio se inserem num Rio de Janeiro cujo tempo-espaço lhe emoldura as ações e lhe oferece os contornos que

\footnotetext{
* Doutor em Literaturas de Língua Portuguesa pela UNESP de São José do Rio Preto, com estágio pós-doutoral em Literaturas de Língua Portuguesa pela UNESP de Assis. Coordenador e professor do curso de Letras e na UEG. Docente no MIELT - Mestrado Interdisciplinar em Linguagem, Educação e Tecnologias da UEG. Líder do Grupo de Pesquisa ERUDIO, desenvolve a linha de pesquisa Literatura e experiência urbana.
} 
configuram sua existência triste e as situações e fatos que, de maneira nítida e depois brumosa, ele rememora. De igual modo é que, em Benjamin (1995), o protagonista que dá nome ao livro vive a opressão de, em seu cotidiano, encontrar-se dividido entre o seu passado e o seu presente em meio a um cenário citadino, local que, ao contrário de propiciar um encontro dele consigo mesmo, radicaliza suas experiências do desencontro, posto que se trata, nessa narrativa, da representação de um espaço urbano cuja constituição torna difícil - quase inviável - tanto a vivência individual quanto a rememoração que dela se faz, o que não deixa de ser uma outra vivência. Também José Costa, em Budapeste (2003), reparte-se entre os espaços citadinos do Rio de Janeiro e de Budapeste, chegando a realizar uma espécie de cartografia emocional desses/nesses dois espaços, na medida em que o processo deambulatório que leva a termo, em ambas as cidades, ocorre de forma paralela às voltas sentimentais que perfaz em seu próprio interior.

Essas figurações da experiência urbana na prosa de Chico Buarque, longe de aproximar os seres e o contexto citadino à sua volta, desvelam aspectos de várias vivências balizadas por questões como a solidão, a ausência de uma total comunicabilidade entre o homem e seus pares, o sentimento de desnorteio, a ausência de sólidas referências familiares, questões que, em seu conjunto, conduzem a uma constante busca por um local de aprazimento e de descanso que jamais é encontrado, já que as cidades criadas pelo autor de Fazenda modelo constituem espaços ambíguos, múltiplos, em que não surge espaço para a plena realização individual.

No contexto narrativo de Estorvo (1991) não é diferente, uma vez que se tem aí o retrato de cenas que se desenrolam tanto pelas ruas de uma grande e inominada cidade quanto por seus arrabaldes, nos momentos em que o protagonista sai da urbe imensa em direção à propriedade rural de sua família. Ressalte-se que tais cenas são vivenciadas por uma personagem que, a despeito ou por causa de suas andanças, não encontra aprazimento e sossego, muito embora não se trate de alguém que anseie por isso ou que pareça ansiar por muitas coisas. Trata-se de um indivíduo sem prazer, sem sonho, sem expectativa: quase um autômato.

Interessante notar, a esse respeito, que não se averigua, nas páginas de Estorvo, a transmissão de uma "Experiência" (Erfahrung - termo sobre cujo sentido Walter Benjamin discorre). Ante a impossibilidade de se ter a experiência tradicional na sociedade burguesa moderna, o que se tem, no livro, é o registro das vivências individuais (Erlebnis - também conforme a formulação benjaminiana). Apesar de não se ter o relato transmissor de um saber recebido como exemplo, proveito, conselho, nos termos propostos pelo estudioso da Escola 
de Frankfurt, pode-se postular que a personagem romanesca - com sua vivência individual -, por ser representação, sinaliza para um campo maior, dialogando com aspectos da vivência de muitos daqueles que acompanharam a narração de seu percurso e, desse modo, torna-se possível afirmar que há uma relação entre a vivência pessoal do protagonista do romance em pauta e os contornos de uma experiência coletiva, esboçados, principalmente, por aqueles que, tendo nascido na cidade, habitam-na, agora, como quem habita um território vago e inconquistável, o cenário mesmo do surgimento de uma sensação desconcertante: a de se habitar um labirinto.

Narrado em primeira pessoa, tem-se, no livro, o relato fragmentário de um indivíduo inominado que se encontra em constante deslocamento pelas ruas da cidade e seus arredores. Ressalte-se que o ritmo de seus passos é correlato ao ritmo fluido e desencontrado de seus pensamentos, e que o movimento um tanto errático de suas andanças dura três dias e meio, durante os quais a fábula oscila entre dois planos, entre o que é e aquilo que parece ser, entre o que se representa e aquilo a que se alude, do que decorre o sentimento de desnorteio da personagem, o qual lhe assalta os sentidos sob a forma de uma angústia, de um aturdimento, o que, no limite, faz com que ela se ponha a caminhar quase a esmo, sem um plano que, previamente, lhe direcione o rumo e a finalidade dos passos.

Nesse sentido, este trabalho objetiva averiguar como se configura, em Estorvo, uma poética urbana do vazio e da errância individual desdobrada por meio das deambulações que o protagonista, atordoado e sem rumo certo, realiza pelas ruas de uma grande cidade. Nesse aspecto, é de nosso interesse constatar os modos pelos quais uma narrativa fragmentada - em seu conjunto e na linguagem que a conforma - se coaduna com o retrato da experiência vivida por uma personagem que, em meio a um cenário urbano - com breves referências a elementos do universo rural -, atravessa pela experiência do deslocamento espacial e da incompreensão mútua, da violência e da impossibilidade de uma plena comunicação com o outro, sempre na condição de um atarantado e perdido flâneur.

\section{A dialética da flânerie em Estorvo}

Em Estorvo, como já se afirmou, tem-se o retrato de uma experiência urbana individual. Tal experiência, porém, adquire feições específicas, já que, além do retrato citadino, tem-se o registro, ainda que por meio de matizes tênues, de uma certa experiência rural, nos momentos em que o protagonista, atordoadamente, se encaminha da cidade para a pequena propriedade rural da família. 
A narração desenvolve-se em níveis: um mais denotativo - com parcimônia no uso dos adjetivos - em que os fatos acontecem e se sucedem, e outro menos denotativo, em que se tem acesso à representação da aparência de tais fatos, os quais são entrevistos por meio do que parece constituir as digressões do narrador-protagonista, aparentes fatos que podem - ou não - serem fruto e reflexo de sua personalidade aturdida e confusa. Cruzam-se, desse modo, no plano da narrativa, os estados de vigília e de sono do protagonista, aos quais são análogas suas percepções ou projeções do real, do que resulta, por fim, o retrato de um real que, ao mesmo tempo, se desdobra e se deforma, como uma realidade que acontece sem parecer que está acontecendo.

Observe-se, nessa perspectiva, que logo no início da obra o leitor é introduzido nessa dimensão narrativa, que oscila entre a realidade e a deformação dessa mesma realidade, por intermédio do constante exercício visual do olhar que a enxerga:

Para mim é muito cedo, fui deitar dia claro, não consigo definir aquele sujeito através do olha mágico. Estou zonzo, não entendo o sujeito ali parado de terno e gravata, seu rosto entumescido pela lente. Deve ser coisa importante, pois ouvi a campainha tocar várias vezes, uma a caminho da porta e pelo menos três dentro do sonho. Vou regulando a vista e começo a achar que conheço aquele rosto de um tempo distante e confuso. Ou senão cheguei dormindo ao olho mágico, e conheço aquele rosto de quando ele ainda pertencia ao sonho. Tem a barba. Pode ser que eu tenha visto aquele rosto sem barba, mas a barba é tão sólida e rigorosa que parece anterior ao rosto. O terno e a gravata também me incomodam. (...) Procuro imaginar aquele homem escanhoado e em mangas de camisa, desconto a deformação do olho mágico e é sempre alguém conhecido mas muito difícil de reconhecer. E o rosto do sujeito assim frontal e estático embaralha ainda mais meu julgamento. Não é bem um rosto, é mais a identidade de um rosto, que difere do rosto verdadeiro o quanto mais você conhece a pessoa. Aquela incomunicabilidade é o seu melhor disfarce para mim. Recuo cautelosamente, andando no apartamento como dentro d'água. (...) Enquanto estou ali ele não toca a campainha, não olha o relógio, não acende o cigarro, não tira o olho do olho mágico. Agora me parece claro que ele está me vendo o tempo todo. Através do olho mágico ao contrário, me vê como se eu fosse um homem côncavo. Assim ele me viu chegar, grudar o olho ao buraco e tentar decifrá-lo, fugir em câmara lenta, os movimentos largos me viu voltar com a fisionomia contraída e ver que ele me vê e me conhece melhor do que eu a ele. (...) Agora ele já percebeu que é inútil, que não me engana mais, que eu não abro mesmo (...) então abana a cabeça e sai da minha visão. E é nesse último vislumbre que o identifico com toda a evidência, voltando a esquecê-lo imediatamente. Só sei que era alguém que há muito tempo esteve comigo, mas que eu não deveria ter visto, que eu não precisava rever, porque foi alguém que um dia abanou a cabeça e saiu do meu campo de visão, há muito tempo. (BUARQUE, 1991, p. 11)

O sujeito cujos contornos o protagonista vislumbra do outro lado da porta é o motivo do constante deslocamento espacial que, a partir desse instante, ele passa a empreender. Constata-se ainda, pela leitura do fragmento, que, embora o narrador-protagonista não duvide de que haja alguém do outro lado da porta de seu apartamento, não chega a ter certeza se conhece ou não o homem que toca a campainha de modo intermitente, e a desfiguração da imagem, que se tem ao se visualizar algo pelo olho mágico, o acompanha ao longo de toda a 
narrativa, como se entre ele e a realidade circundante houvesse uma lente, intermediando e borrando sua percepção dessa mesma realidade.

Desse modo, da mesma maneira por meio da qual o referido narrador enxerga a imagem distorcida do homem de terno e gravata que estava de pé, do outro lado de sua porta, igualmente distorcidas parecem ser tanto sua própria imagem quanto a das demais personagens, bem como a da cidade e a do sítio de sua família: trata-se, pois, de seres e de lugares que são entrevistos por meio de um prisma algo embaçado, difuso e incerto. Nesse aspecto, o motivo do olho mágico metaforiza a condição tanto do protagonista quanto dos demais elementos - espaço e personagens - da narrativa: todos são um tanto vagos, um tanto difusos, um tanto esfumaçados, seres e lugares que se postam no entre-lugar do sono e da vigília, da nitidez e do embaçamento.

Dessa maneira é que, tanto nos momentos em que ele perambula pelas ruas da cidade quanto nos instantes em que se encaminha até o sítio da família, é incapaz de realizar uma leitura plena e objetiva do real que o cerca e com o qual, diga-se, interage de modo vago, atordoado, entorpecido, mas, nem por isso, de modo menos contundente: sua realidade, $\mathrm{s}$ despeito de ser vaga, é o que lhe move e o que e o sufoca.

Observe-se que, na medida em que o protagonista, como já se afirmou, perfaz um movimento errante, sem destino certo, caminhando, se não a esmo, pelo menos sem um rumo previamente pensado, acaba por vivenciar instantes de caminhada que o aproximam da figura do flâneur parisiense do século XIX, do qual nos fala Walter Benjamin em Charles Baudelaire: um lírico no auge do capitalismo (1989) ${ }^{1}$.

Assim, torna-se válido afirmar que o seu comportamento o aproxima tanto da figura do flâneur parisiense, quanto daquilo que o estudioso da Escola de Frankfurt caracteriza, de modo mais específico, como a dialética da flânerie: o indivíduo em cujo comportamento se nota, por um lado, o temor de tudo e de todos e, por esse motivo, põe-se a caminhar sem um rumo previamente definido, sentindo-se simplesmente o suspeito e, por outro lado, percebe-se completamente insondável, oculto e protegido de perseguidores que, muitas vezes, são seres imaginários:

Já não tocará a campainha; desintegrará a fechadura, eu na calçada oposta. (...) Não preciso olhar o sexto andar para saber que ele me vigia da minha janela. Verá que aperto o passo e sumo correndo na primeira à esquerda. E chamará o elevador, e chamará o táxi, mas não convencerá o motorista a me perseguir na contramão. Tentará uma paralela, mas eu me emboco no túnel, alcanço outro bairro, respiro novos ares. Empacará no trânsito e eu subo as encostas, as prateleiras da floresta, as ladeiras invisíveis de onde se avista a cidade inteira. (BUARQUE, 1991, p. 14)

\footnotetext{
${ }^{1} \mathrm{O}$ estudo original de Walter Benjamin data da década de 30 do século passado.
} 
Tem-se, no excerto acima, o esboço de um plano que caracteriza, em sua configuração, o intento de um indivíduo cujo comportamento se insere na dialética da flânerie, na medida em que ele tanto almeja fugir do homem que tocava sua campainha, sentindo-se, de algum modo, perseguido, vítima de algum perigo iminente, quanto se sente, até certo ponto, seguro ou, mesmo, invisível para o olhar de seu suposto perseguidor, o que aconteceria tão logo ele alcançasse as "ladeiras invisíveis" de onde se avistava toda a cidade, ou seja, ele vê o seu suposto perseguidor, mas não é visto, o que não deixa de lhe conferir alguma sensação de sossego, alguma vaga noção de segurança e, no limite, alguma impressão de paz, ainda que ilusória.

No que diz respeito ao deslocamento espacial de seres ficcionais pelas ruas e becos da cidade, Regina Dalcastagnè assevera que não basta segui-los em seu constante trajeto pelas ruas citadinas, mas que devemos "correr atrás deles pelos engarrafamentos da cidade, alcançar autoestradas, tomar trens, aviões, navios, persegui-los por continentes e tempos diferentes, esbarrando muitas vezes no sem sentido de seu percurso, reflexo do sem sentido de sua existência." (DALCASTAGNÈ, 2003, p. 39).

Ainda conforme a estudiosa, quanto mais velozmente acontece o deslocamento, menor a profundidade por meio da qual se efetua a representação do espaço urbano, com todas suas peculiaridades, pois não se percebem nem as transformações desse espaço nem as dos elementos da paisagem que o compõem, tendendo a "construção a virar só fachada" (DALCASTAGNÈ, 2003, p. 39).

Isso nos remete à aparente diluição dos elementos espaciais no contexto narrativo de Estorvo, uma vez que se tem, no romance, não o retrato de uma cidade específica, nominada, com seus prédios, ruas igualmente nominadas e becos bem demarcados e delimitados, mas, sim, a construção narrativa de um espaço vago, genérico e, por vezes, conformado por contornos imprecisos, já que, não raro, as descrições do espaço nascem da perspectiva desnorteada e algo difusa do protagonista.

Levando em conta o constante deslocamento espacial do narrador-personagem - cujo olhar também se encontra sempre em trânsito - nota-se a existência textual de um indivíduo desterritorializado, que se entrega a um tipo de peregrinação pelas ruas de sua cidade e pelos trilhos do sítio de sua família perfazendo uma mobilidade espacial que, se não se constitui como exemplo de um processo migratório, seja de um país para o outro, seja de um território para o outro dentro de uma mesma nação - no caso brasileiro, geralmente das zonas nordestinas para o centro-sul -, seja de um espaço rural para um espaço urbano, nem por isso 
ele deixa de se configurar como uma personagem deslocada e um tanto perdida, chegando, mesmo, a sofrer alguns dos entraves advindos de mudanças e deslocamentos geográficos, como dificuldades de adaptação e a conseqüente perda de referenciais.

Embora não se trate de um indivíduo que realiza uma mudança no sentido de se deslocar territorialmente - mudar-se de um lugar para outro -, o narrador-personagem também se caracteriza como alguém desterritorializado, na medida em que não encontra, para si, um espaço cuja configuração lhe diga alguma coisa, no sentido de lhe sinalizar algo com o que possa se identificar, se sentir seguro, se sentir em casa. Ao contrário: justamente por não se sentir a salvo dentro de sua residência, é que se põe a caminhar, fugindo de alguém sem rosto, sem nome, fugindo e tentando se esconder de um indivíduo que, talvez, seja fruto de sua própria imaginação.

Nessa perspectiva, se o comportamento do flâneur parisiense era o de alguém que se deixava guiar movido pelo princípio do prazer, o qual se traduzia na relação de amor e admiração que ele mantinha pelas construções arquitetônicas e pelos paralelepípedos do calçamento de sua cidade, as caminhadas - erráticas - do narrador-protagonista deixam-se reger por sua premente necessidade de encontrar um sentido para o não sentido sob cuja égide se posta sua existência e, correlatamente, também a existência da cidade dentro de cujos muros invisíveis ele, de maneira atabalhoada, sente-se perseguido e prisioneiro.

\section{Experiência urbana em Estorvo}

De acordo com Luis Alberto Ferreira Brandão Santos, a cidade, na literatura contemporânea, não aparece somente "como cenário para o desenrolar de um enredo, mas, também, na condição de agente determinante da significação da narrativa como um todo. A cidade surge, assim, enquanto personagem" (SANTOS, 1999, p. 32).

Verificam-se, portanto, estreitas correlações entre os seres ficcionais e o contexto urbano que lhes serve de palco para as ações, sobretudo porque é a partir dessas correlações que elementos espaciais tornam-se elementos significativos na constituição da identidade das personagens.

Desse modo é que, nas páginas de Estorvo, a um narrador-personagem inominado e carente de um sentido histórico-social em relação a sua própria vida, correspondem um espaço urbano e um espaço rural igualmente inominados - ou nominados de forma genérica, pois são a cidade e o sítio, apenas -, bem como desprovidos, esses espaços, de uma representação espacialmente mais objetiva ou menos vaga, menos fluida. 
Em seu estudo sobre o espaço narrativo e os efeitos de ambientação que dele podem decorrer, Tomachévski (1965) considera que, relativamente ao modo como personagens e espaço dialogam, pode haver dois tipos de ambientação: a heteróloga e a homóloga.

A primeira diz respeito ao fato de haver relações opostas entre o estado de ânimo das personagens e o espaço em que elas estão: a alegria de um casal de namorados que passa em frente a uma casa em que se realiza um velório, por exemplo, e, a segunda, diz respeito ao fato de existirem relações de homologia, de similitude entre o espaço e o estado anímico das personagens: um casal de namorados que se diverte num parque florido, sob um cálido sol de abril, por exemplo.

Levando em conta essas considerações, verifica-se que, quando o narradorprotagonista de Estorvo assiste a uma partida de tênis, na casa de sua irmã, sentado em uma cadeira "verde e pernalta de juiz", narra que tem

Fixo o olhar no muro, ouço a bola que saltita no piso sintético, para lá e para cá, para lá e para cá, a voz do meu cunhado cada vez mais remota, e parece que estou sendo alçado aos poucos, como se minha cadeira estivesse numa grua. Ou será o meu cunhado que afunda devagar numa cratera, sucumbindo a uma avalanche de bolas de tênis. Desperto quando ele atira a raquete no chão e diz "assim eu me desconcentro". Eu não fiz nada, estava só pensando, mas logo vejo que a culpa é do copeiro, que acaba de entrar na quadra sem pedir licença (BUARQUE, 1991, p. 116).

Não nos parece gratuito o fato de, nesse trecho, a personagem presenciar um jogo de tênis em cuja consecução observa a bola que, impulsionada pelas raquetes, põe-se "para lá e para cá, para lá e para cá”, completando um contínuo e aprisionador movimento de vai e volta, o que parece metaforizar a própria condição da personagem, que, de modo igualmente contínuo e aprisionador, transita tanto pelas ruas da cidade quanto perpassa os limites da cidade e do campo sem, contudo, jamais encontrar um pouso, um lugar de descanso.

O que decorre dessa carência de um lugar onde se possa repousar ou, mesmo, de um lugar que se configure como o destino final dos passos algo incertos e confusos do protagonista, é um sentimento de desnorteio que, embora o assalte em todos os momentos, o faz de modo vago, como se ele não tivesse consciência exata de que é um ser desnorteado.

Observe-se, ainda, que a essa sensação de indizível desnorteio, por parte do herói do romance, corresponde um espaço que pode ser em si mesmo um outro desnorteio, na medida em que não sinaliza qualquer orientação para os sentidos, antes configurando-se como um local que porta as funções de um labirinto cuja saída não se dá a conhecer: um espaço urbano de confusão e descaminho, como se a cidade de Babel tivesse saído do contexto bíblico para habitar as páginas do livro de Chico Buarque. 
Cumpre observar, ainda, que, conquanto esteja perdido em seus próprios enleios, confuso e atabalhoado, o narrador transita por locais citadinos em que, se por um lado ele quase se perde, por outro lado se deixa guiar pelas marcas, pelos signos desses mesmos locais, no sentido de transitar por lugares que reconhece. O que ele não conhece, e disso sequer tem ideia, é o destino final ao qual seus passos errantes o conduzirão.

Se o retrato do urbano, nesse primeiro romance de Chico Buarque, não emoldura cenas felizes para o narrador-protagonista, o mesmo pode-se afirmar do retrato do universo rural, já que o sítio que figura no presente da narrativa não é o mesmo cujas peculiaridades pontuam algumas lembranças antigas do referido narrador.

Nesse sentido, após ter se afastado dos limites da cidade em direção ao campo, movido por uma necessidade de ter que se encaminhar para algum lugar, ele, tão logo chega à casa da fazenda, afirma:

\begin{abstract}
Encontro aberta a cancela do sítio me perturba. Penso nos portões dos condomínios, e por um instante aquela cancela escancarada é mais impenetrável. Sinto que ao cruzar a cancela, não estarei entrando em algum lugar, mas saindo de todos os outros. Dali avisto todo o vale e seus limites, mas ainda assim é como se o vale cercasse o mudo e eu agora entrasse num lado de fora. (BUARQUE, 1991, p. 24)
\end{abstract}

É um tanto difícil, para ele, cruzar a porteira do sítio e, ao que parece, entrar na propriedade tanto pode sinalizar sua ida para algum tipo de refúgio quanto para alguma modalidade de prisão, na medida em que afirma sentir que não está "entrando em algum lugar" e, sim, que está "saindo de todos os outros", ou seja, o adentrar a cancela aberta constitui em si mesmo um ato de voltar as costas a todos os outros locais que não sejam o sítio, o que acaba por conferir, a esse local, um certo caráter de fuga, de retiro ou, mesmo, de esconderijo. $\mathrm{O}$ ato de abrir a cancela e adentrar esse espaço rural simboliza, ainda, o voltar as costas à cidade e às suas conquistas, o que parece abrir um questionamento atual acerca de algumas promessas de realização e crescimento pessoal que a cidade moderna fez a quem para seus domínios se encaminhasse, promessas que o decurso histórico provou terem sido ilusórias (IGNÁCIO, 2010).

Prosseguindo a narrativa, tem-se o retrato daquilo que realmente espera pelo protagonista na propriedade rural da família:

Olho para os lados pensando no velho, mas o velho não está. O dos anéis pergunta quem eu penso que sou e que porra eu faço naquela propriedade. Vejo as crianças enfileiradas no alto do sítio, perto do riacho. Olho para o chão, e estou descalço, não tive tempo de me vestir direito. Os dois comparsas começam a esfregar suas botas nas tábuas da varanda, como se apagassem charutos, e com isso produzem um chiado desagradável. O chefe enfia a mão no forro do casaco de couro, vai sacar alguma coisa ali de dentro. (BUARQUE, 1991, p. 32) 
O cenário com o qual ele se depara, ao chegar à casa do sítio, é o de um local abandonado, decrépito e invadido por bandidos que, inclusive, acabam por expulsá-lo de lá, chegando a ameaçá-lo de morte. De refúgio, nada mais resta da antiga propriedade campestre. De refúgio, também, o campo retratado em Estorvo não tem nada. É, antes, o espelho da própria cidade: babélico local de estupefação e esmaecimento, um embaçado espelho cujos reflexos demonstram que as distâncias entre o rural e o urbano, na contemporaneidade, praticamente inexistem, como se a formulação de Raquel Rolnik (2004) acerca do desenvolvimento urbanístico, que cada vez mais tenderia a se apropriar do espaço como um todo, urbanizando toda a sociedade, já tivesse, de fato e inelutavelmente, acontecido.

Depois de ser expulso do sítio, o protagonista retorna para a cidade, local onde dá prosseguimento às suas andanças de "flâneur dos trópicos", de um caminhante que, nas malhas do urbano, não realiza nem uma cartografia emocional, nem um aprendizado: apenas caminha, apenas caminha sem rumo certo.

\section{Todos os fins, o fim}

Raymond Williams (1989) postula que não só a cidade e o campo sofreram a influência do capitalismo, mas a própria sociedade moderna como um todo, e que disso adveio uma sensação de isolamento que, por sua vez, encontra-se também intimamente vinculada às formas de competição e, no limite, de alienação que o sistema capitalista promove.

Nesse sentido, na medida em que o protagonista de Estorvo não parece sequer ter uma profissão - vive de doações de cheques da irmã -, nem se preocupa em se inserir no mercado de trabalho, acaba por se assemelhar com o que parece ser uma peça solta - e enferrujada - na engrenagem do sistema capitalista, para cujos valores ele seria, facilmente, taxado de acomodado, de preguiçoso e, no limite, de vagabundo.

Seja como for, sua condição, a de um indivíduo que se coloca à margem das coisas, acaba por fazer com que ele se torne uma pena solta na cidade, porque afinal trata-se de alguém que caminha, erraticamente, ao sabor de uma incerteza e de um desnorteio: trata-se de um ser que prescinde de um paradeiro fixo, de um ser que não tem perspectiva e nem noção de que caminha sem uma causa e sem um rumo certos. A experiência urbana que ele realiza, portanto, é uma experiência contundente, porém inútil, pois se ele não tem noção exata de que vivencia os fatos, é como se não os vivesse, e, se não lê os acontecimentos de que participa, até mesmo os que acontecem à sua volta, por extensão não realiza uma apreensão da cidade, 
nem detecta "o fio condutor de seu discurso, o seu código interno" (GOMES, 1994, p. 50). Nesse aspecto, a cidade que, para Barthes (1987), é também texto e fonte de leitura, para o protagonista de Estorvo é um espaço vago e difuso, ou melhor: uma página em branco.

Constata-se ainda, no romance, que tanto a cidade quanto o campo configuram-se como locais des-referencializados e extremamente vagos, posto que entrevistos pelo olhar do protagonista, um olhar deformado e deformante desde o início da narrativa.

Além de vagos, esses dois espaços conformam ambientes nos quais o indivíduo não se realiza de modo algum, o que parece ocorrer, fundamentalmente, por dois motivos: porque são espaços que, há muito, rechaçaram quaisquer ilusões que se pudesse nutrir sobre eles e também porque, diferentemente do sujeito moderno, que nutria idealizações e ilusões acerca de si mesmo e acerca da cidade que crescia e que lhe prometia êxitos pessoais a todo instante, bem como acerca do campo em cujos domínios a excelência da tecnologia e da técnica parecia impor-se como dádiva, o protagonista constitui-se como um sujeito que não espera, não sonha, não idealiza. Apenas vai vivendo e caminhando, na opaca condição de um sujeito quase autômato.

E caminha até o final da narrativa, momento em que se depara com seu destino - seria realidade ou alucinação? -, ao qual faz eco sua própria condição na narrativa: um ser ambíguo, que transita pelo território do devaneio e da concretude. Ao retornar, pela última vez, do sítio para a cidade, ele revê uma personagem, o "homem magro da camisa quadriculada", experimentando, nesse momento, um estranho "sentimento de gratidão" e, então, abre os braços para abraçá-lo, sendo recebido com um duro golpe de um "facão de cozinha enferrujado" (BUARQUE, 1991, p. 140). Vertendo sangue, ele sobe ao ônibus, pensando em, quando chegar à cidade, pedir mais dinheiro à irmã, a fim de se sustentar por mais seis meses; pensa também em ligar para a mãe e, se ela não puder falar com ele, procurar o amigo; se ele tiver morrido, procurar a ex-mulher, para que ela possa tratar de seu ferimento. E o seu relato se fecha, ficando, o leitor, sem saber se ele sobreviveu ou não ao seu ferimento.

A narrativa se fecha, emblematicamente, no exato instante em que o narradorpersonagem se encontra dentro de um ônibus, saindo do campo em direção à cidade, ou seja, encerra-se no preciso instante em que ele não está nem em um, nem em outro local, mas, sim, numa espécie de entre-lugar, o que parece metaforizar sua própria condição de um sujeito sem direção, sem espaço e sem paradeiro certos, sua própria condição de um ser errante. Errante e vazio. 


\section{Referências}

BARTHES, Roland. A aventura semiológica. Trad. Maria de Santa Cruz. Lisboa: Edições 70, 1987.

BENJAMIN, Walter. Obras escolhidas II: Rua de mão única. Trad. Rubens Rodrigues Torres Filho e José Carlos Martins Barbosa. São Paulo: Brasiliense, 1987.

. Obras escolhidas III: Charles Baudelaire: um lírico no auge do capitalismo. Trad. José Carlos Martins Barbosa e Hemerson Alves Baptista. São Paulo: Brasiliense, 1989.

BUARQUE, Chico. Estorvo. São Paulo: Companhia das Letras, 1991.

DALCASTAGNÈ, Regina. Sombras da cidade: o espaço na narrativa brasileira contemporânea. In: Revista Estudos e literatura brasileira contemporânea. vol. 1, n. 21. Brasília, p. 33-54, jan/jul, 2003.

GOMES, Renato Cordeiro. Todas as cidades, a cidade: literatura e experiência urbana. Rio de Janeiro: Rocco, 1994.

IGNÁCIO, Ewerton de Freitas. Do campo abandonado para a cidade suportada: campo e cidade na literatura brasileira. Anápolis: Ed. Universidade Estadual de Goiás, 2010.

ROLNIK, Raquel. O que é a cidade. São Paulo: Brasiliense, 2004.

SANTOS, Luis Alberto Brandão. Textos da cidade. In: COELHO, Haydeé Ribeiro; VASCONCELOS, Maurício Salles (Orgs.). 1000 rastros rápidos: cultura e milênio. Belo Horizonte: Autêntica, 1999. p. 131-138.

TOMACHEVSKI, B. et al. "Thématique". In: TODOROV, T. (org.). Théorie de la literature. Paris: Seuil, 1965.

WILLIAMS, Raymond. O campo e a cidade na história e na literatura. São Paulo: Companhia das Letras, 1989. 